\title{
A reliability assessment of physical vulnerability of reinforced concrete walls loaded by snow avalanches
}

\author{
P. Favier ${ }^{1,2}$, D. Bertrand ${ }^{1}$, N. Eckert ${ }^{2}$, and M. Naaim ${ }^{2}$ \\ ${ }^{1}$ INSA de Lyon, Laboratoire de Génie Civil en Ingénierie Environnementale, 34 avenue des Arts, 69621 Villeurbanne, France \\ ${ }^{2}$ IRSTEA, UR ETNA, 2 rue de la papeterie BP 76, Université Grenoble Alpes, 38402 Saint-Martin-d'Hères Cedex, France \\ Correspondence to: P. Favier (philomene.favier@irstea.fr), D. Bertrand (david.bertrand@insa-lyon.fr), \\ N. Eckert (nicolas.eckert@irstea.fr), and M. Naaim (mohamed.naaim@irstea.fr)
}

Received: 16 April 2013 - Published in Nat. Hazards Earth Syst. Sci. Discuss.: 7 June 2013 Revised: - Accepted: 5 February 2014 - Published: 27 March 2014

\begin{abstract}
Snow avalanches are a threat to many kinds of elements (human beings, communication axes, structures, etc.) in mountain regions. For risk evaluation, the vulnerability assessment of civil engineering structures such as buildings and dwellings exposed to avalanches still needs to be improved. This paper presents an approach to determine the fragility curves associated with reinforced concrete (RC) structures loaded by typical avalanche pressures and provides quantitative results for different geometrical configurations. First, several mechanical limit states of the RC wall are defined using classical engineering approaches (Eurocode 2), and the pressure of structure collapse is calculated from the usual yield line theory. Next, the fragility curve is evaluated as a function of avalanche loading using a Monte Carlo approach, and sensitivity studies (Sobol indices) are conducted to estimate the respective weight of the RC wall model inputs. Finally, fragility curves and relevant indicators such a their mean and fragility range are proposed for the different structure boundary conditions analyzed. The influence of the input distributions on the fragility curves is investigated. This shows the wider fragility range and/or the slight shift in the median that has to be considered when a possible slight change in mean/standard deviation/inter-variable correlation and/or the non-Gaussian nature of the input distributions is accounted for.
\end{abstract}

\section{Introduction}

The increasing urban development in mountainous areas means that issues associated with rockfalls, landslides and avalanches need to be addressed (Naaim et al., 2010). Prospective human casualties and physical civil engineering structures damages are of concern for snow avalanche risk management. Depending on the external loading applied to the structure, that is to say the natural hazard considered (rockfall, landslide, earthquake, etc.), the physical vulnerability of civil engineering structures is usually assessed differently depending on the nature of the failure modes involved. If a relevant failure criterion is defined that represents the overall damage level of the structure, the potential failure of the system can be assessed and even its failure probability if the calculations are performed within a stochastic framework.

Avalanche risk mapping is often carried out by combining probabilistic avalanche hazard quantification (e.g., Keylock, 2005; Eckert et al., 2010) and vulnerability (deterministic framework) or fragility (probabilistic framework) relations to assess individual risk for people (Arnalds et al., 2004) and buildings (Cappabianca et al., 2008). For instance, the Bayesian framework (Eckert et al., 2009, 2008; Pasanisi et al., 2012) makes it possible to take into account uncertainties in the statistical modeling assumptions and data availability. On the other hand, a better definition of vulnerability or fragility relations remains a challenge for the improvement of the integrated framework of avalanche risk assessment (Eckert et al., 2012). 
A review of vulnerability approaches for alpine hazards (Papathoma-Köhle et al., 2010) mentioned various studies conducted to derive vulnerability relations. Several definitions have been proposed. One point of view is to define the vulnerability of a structure by its economic cost and not its physical damage (Fuchs et al., 2007), which necessitates an expression for the recovery cost (Mavrouli and Corominas, 2010). Another point of view suggests that human survival probability inside a building is commonly related to the vulnerability of the building itself by empirical relations (Jonasson et al., 1999; Barbolini et al., 2004). For instance, Wilhelm (1998) introduced thresholds to build vulnerability relations for five different construction types impacted by snow avalanches, and Keylock and Barbolini (2001) proposed relating the vulnerability of buildings with their position in the avalanche path. More recently, Bertrand et al. (2010) suggested using a deterministic numerical simulation to assess the structural failure susceptibility of reinforced concrete (RC) structures.

To describe the failure probability of civil engineering structures exposed to snow avalanches and thus derive fragility curves, reliability approaches can be considered. For instance, in earthquake engineering (Ellingwood, 2001; Li and Ellingwood, 2007; Lagaros, 2008) or for RC structures subjected to blast loading (Low and Hao, 2001), the latter technique is often used. In hydraulic risk research, some studies focus on assessing dam safety using reliability methods (Peyras et al., 2012). Direct simulations (such as Monte Carlo methods) give robust results but can be timeconsuming. As an alternative, simulation-based or surface approximation methods are used to avoid the direct calculation of the failure probability (Lemaire, 2005), but convergence of the algorithm can be cumbersome.

In the snow avalanche context, vulnerability relations are often derived from back-analyzed in situ data, which are often very scarce. These relations give the fraction of destroyed buildings as a function of the avalanche loading. A reliability assessment of vulnerability relations (fragility curve derivation) is therefore a useful complementary tool for examining the interaction between the avalanche and the structures at different scales (avalanche path, urban area, individual house, etc.). This paper attempts to improve risk evaluations by proposing an innovative way to derive refined fragility curves that can be used in snow avalanche engineering.

As RC is the most usual material used to build structures exposed to potential avalanche loadings, herein we focus on this technology. First of all, the RC structure is described. Secondly, the mechanical model of the RC wall and the snow avalanche loading description are exposed. Then, the damage level definitions opted for in the structure limit state description are presented. The next part deals with statistical distributions of the inputs of the deterministic mechanical model. Finally, fragility curves are derived and their sensitivity to input parameters, modeling assumptions and failure criterion are discussed.

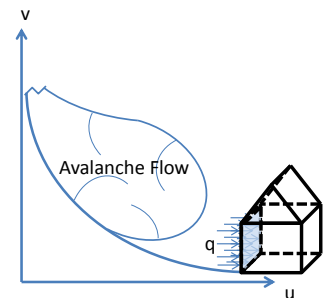

(a)

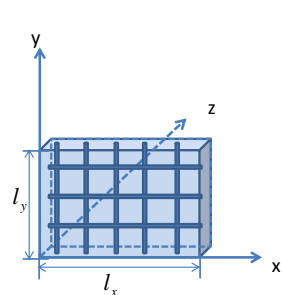

(b)

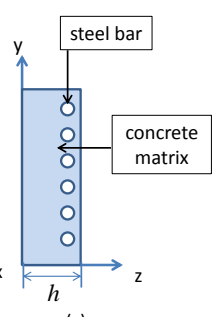

(c)
Fig. 1. Dwelling house impacted by a snow avalanche: loading applied onto the structure (a); RC wall geometry and orthogonally distributed reinforcement (b-c).

\section{Methods}

To protect people against snow avalanches, French legal hazard zoning defines three regions, which correspond to several levels of danger. The white zone corresponds to the geographic zone where the consequences of an avalanche in terms of structural damage have been estimated negligible. Hence, no specific recommendations related to the ability of the structure to resist to an avalanche are needed. In the red zone, the avalanche return period has been estimated less than $100 \mathrm{yr}$ and thus no construction is allowed. In the last zone (blue zone), civil engineering structures, such as buildings or houses, can be built only within certain restrictions. For the wall facing the avalanche, no opening is allowed and the wall has to resist at least a pressure of $30 \mathrm{kPa}$. Several technologies are available. As mentioned by Givry and Perfettini (2004), the most common are wooden, masonry, RC or mixed structures. RC technology appears to provide the best value for money. Moreover, RC is usually the most frequently encountered material for such structures and in particular for dwelling houses. The most vulnerable part of a structure built in an avalanche path is the wall facing the flow (Fig. 1). Thus, the damage of the entire structure can be assessed from the wall's resistance capacity. Indeed, the pressure applied by the avalanche flow on the structure is balanced almost solely by the wall facing the avalanche. Thus, as a first approximation, the damage of the entire structure is reduced to the damage of the structural elements directly exposed to the load, i.e., a flat vertical RC wall.

\subsection{RC wall description}

First, the features of the wall considered are presented (geometry, mechanical properties of reinforced concrete, boundary conditions). Then, the out-of-plane mechanical response of an RC wall is described. The nature of the damage and the different damage stages the structure undergoes are presented as a function of the loading magnitude. From the physical vulnerability assessment point of view, relevant performance functions dedicated to quantifying the damage level of the 
$\mathrm{RC}$ wall can be proposed. Finally, the wall loading due to a snow avalanche is presented and discussed.

\subsubsection{RC wall features}

The $\mathrm{RC}$ wall is composed of concrete and steel bars. The bars are distributed homogeneously along the horizontal and vertical directions in the region of the wall where tensile stresses can develop (Fig. 1b-c). The number of steel bars is calculated from the steel density $\left(\rho_{\mathrm{s}}\right)$ needed to ensure the resistance of the RC wall. The usual sizes of dwelling houses situated in mountainous regions have been considered. Depending on the construction solution chosen, the RC wall boundary conditions can vary from one dwelling to another. The modeling of such various technologies of construction is considered in the boundary conditions of the wall. Three kinds of boundary conditions are usually encountered. Each edge of the wall can be considered either simply supported or clamped or free (e.g., can move without any constraint). From a mechanical point of view, concrete strength differs from compressive to tensile regimes. The characteristic compressive strength $\left(f_{\mathrm{c} 28}\right)$ is generally 10 times greater than the tensile strength $\left(f_{\mathrm{t}}\right)$. The compressive strength allowable for calculation is defined as $f_{\mathrm{bc}}$ by the Eurocode 2 (Committee, 2004), as a function of the loading time parameter, i.e., the creep consideration, $\theta$ and the safety factor $\gamma_{b}$ described below:

$f_{\mathrm{bc}}=\frac{0.85 f_{\mathrm{c} 28}}{\theta \gamma_{\mathrm{b}}}$.

Steel's behavior exhibits two typical limits. First, the yield strength $\left(f_{\mathrm{y}}\right)$ exceeding corresponds to the development of permanent strain inside steel; secondly, the ultimate tensile strain $\left(\epsilon_{\mathrm{uk}}\right)$ highlights the ability of steel to undergo more or less substantial yield strain before failure. The RC behavior is a combination of the two materials. Figure 2 depicts the typical evolution of an $\mathrm{RC}$ member subjected to a monotonic loading. Four stages can be identified. The first stage represents the elastic response of the RC wall. The second stage corresponds to crack appearance and growth in the tensile zone of concrete. Once the crack distribution is fully developed (beginning of stage 3 ), the opening of the cracks continues. For higher loading and for low reinforced concrete, the capacity of the RC wall is only controlled by the resistance of the steel bars. When a steel bar starts to undergo plastic strain, it is the beginning of the fourth stage. The end of the stage 4 corresponds to the collapse of the RC wall, where strains are concentrated through yield lines that can be described as macro-cracks. At the scale of the RC member, this last stage ends when a typical fracture line pattern develops over the entire RC structure. This failure mechanism induces the structure's loss of equilibrium, leading to its collapse.

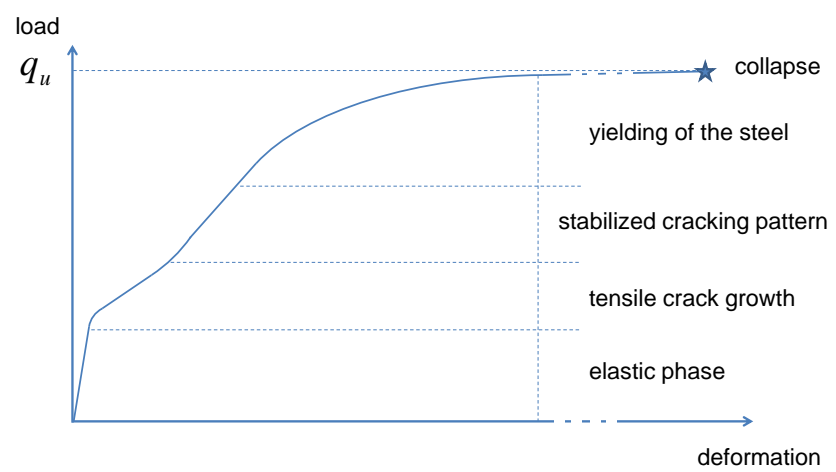

Fig. 2. Typical mechanical response of RC members subjected to a pushover test (monotonic loading until the collapse of the system), derived from (Favre et al., 1990, p. 343).

\subsubsection{Limit state definitions}

The structural failure is assumed to be due to excessive bending of the wall. The RC wall collapses under a bending failure mode. The first damage level is defined as when the RC wall is no longer elastic. See for instance the European standard dedicated to the design of RC members: the Eurocode 2 provides mechanical design recommendations for several types of loadings. In this paper, the mechanical states used to describe the damage level of the structure are inspired from the Eurocode 2. The second and third damage levels are defined from Eurocode 2 (Mosley et al., 2007), where typical safety coefficients are proposed. Finally, the collapse of the RC wall is modeled by yield line theory (Johansen, 1962). It allows for calculating the ultimate pressure that the structure can support before collapse. The first three stages are defined from the local mechanical balance of the cross section where the highest bending moment arises, whereas stage 4 considers the whole failure pattern of the wall.

\section{Elastic limit state}

The first crack in the concrete defines the upper limit of stage 1. Beyond the first stage upper limit, the RC wall is no longer elastic. This limit is defined as when the tensile stress inside the concrete is reached.

\section{Ultimate limit state (ULS)}

This mechanical state is defined in the Eurocode 2 regulation and concerns the safety of people inside buildings and that of the building itself. In this paper, the Eurocode 2 terminology is used, but it can be a bit confusing. Indeed, the ULS does not correspond to the "real" ultimate resistance of the RC wall, which is here assessed by the yield line theory (see Sect. 2.1.2). From the Eurocode 2, the ULS is related to potential loadings that can arise during the "normal" life of the RC wall. The loadings are either permanent or transitory but not exceptional. Thus, the safety factors associated 
Table 1. Safety coefficients on steel and concrete strength for ULS and ALS calculations (Committee, 2004).

\begin{tabular}{lll}
\hline & ULS safety coefficient & ALS safety coefficient \\
\hline Steel & $\gamma_{\mathrm{s}}=1.15$ & $\gamma_{\mathrm{s}}=1$ \\
Concrete & $\gamma_{\mathrm{b}}=1.5$ & $\gamma_{\mathrm{b}}=1.15$ \\
\hline
\end{tabular}

to the ULS loading are calculated based on "normal" life of the structure. Under bending, the ultimate limit state is obtained when either the concrete reaches its ultimate compressive strain or the steel its ultimate tensile strain.

\section{Accidental limit state (ALS)}

When dimensioning, the ALS differs from the ULS only in the loading description. Loadings are assumed exceptional (i.e., accidental) and not usual or "normal" as for the ULS. The probability of occurrence of such loadings is often low and explains why the safety factors are lower than in the ULS case and thus the margin to support the loading is lower (Table 1). Using ALS as a structural limit state the structure could reach consists in applying a different multiplicative safety coefficients on the strength of the two materials comparing to those applied in the ULS approach.

\section{Collapse}

Finally, the collapse of the structure is characterized by its failure pattern. Under bending, yield lines develop through the RC member, leading to the structure's collapse. In order to obtain the ultimate load, the yield line theory is used, which is based on limit analysis theory (see for instance Nielsen and Hoang, 2011). In the literature, some theoretical and experimental studies have been compared. These studies proposed collapse failure patterns as a function of boundary conditions (Sawczuk and Jaeger, 1963). Favre et al. (1990) provide theoretical solutions for RC slabs under various geometrical configurations.

\subsubsection{Snow avalanche loading}

Different types of avalanche flows can be observed in the Alps, inducing various loadings on the impacted structures. Spatial and temporal changes in snow avalanche loadings were experimentally observed and measured. For instance, small-scale experiments were conducted to reproduce the granular behavior of snow and study its interaction with obstacles (Faug et al., 2010). Moreover, real-scale experiments have been conducted to measure the pressure magnitudes reached by dense avalanche flows (Thibert et al., 2008) and powder avalanches (Sovilla et al., 2008).
An open question concerning the physical vulnerability assessment of civil engineering structures is whether the problem should be considered with a dynamical approach or a quasi-static approach. Various studies (Daudon et al., 2013) have considered that the dynamic effect has to be taken into account, whereas others have obtained vulnerability results assuming quasi-static approaches (Bertrand et al., 2010). In addition, in some cases (powder avalanches for instance) negative pressures can arise during the loading and thus can modify the failure mode of the structure considered. However, as already suggested, the type of avalanche controls the type of loading (quasi-static or dynamic), and here the avalanche type is considered as dense, which cannot generate negative pressures.

To determine whether a dynamic or a quasi-static approach has to be considered, a modal analysis has to be performed to compare avalanche loading and structural natural periods. In this paper, it is assumed that the duration of the accidental loadings is not creating dynamical effects. Thus, the pressure of the avalanche is supposed to be quasi-static, as proposed by Bertrand et al. (2010). Moreover, a uniform pressure distribution is applied to the wall even if vertical variations are observed (Baroudi et al., 2011). The pressure is uniformly distributed on the entire facing wall, along $x$ and $y$ axes. Due to the quasi-static assumption, the response of the $\mathrm{RC}$ wall is calculated considering the maximal pressure reached over time. The time variation is not considered because only the peak pressure for a quasi-static approach is relevant. The assumption of uniform pressure distribution is conservative, since the maximum is applied over the entire vertical, whereas in reality it decreases with the vertical coordinate.

\subsection{Mechanical approaches}

Figure 3 depicts the transitions between each damage level (Elas: elastic limit; ULS: ultimate limit state; ALS: accidental limit state; YLT: yield line theory). For each point, a loading pressure $\left(q_{\mathrm{Elas}}, q_{\mathrm{ULS}}, q_{\mathrm{ALS}}, q_{\mathrm{YLT}}\right)$ can be calculated. For the first three cases, the load is obtained from the mechanical balance of the cross section, which is subjected to the maximal bending moment inside the RC wall (Fig. 4). For the collapse load, yield line theory is used.

\subsubsection{RC wall design under bending}

\section{Bending moment expression}

First, the loss of RC elasticity is related to crack appearance when the tensile strength of concrete is exceeded. At this stage, the steel contribution in the overall behavior can be ignored. The bending moment can thus be expressed as

$M_{\text {Elas }}=\frac{f_{\mathrm{t}} l_{x} h^{2}}{6}$. 


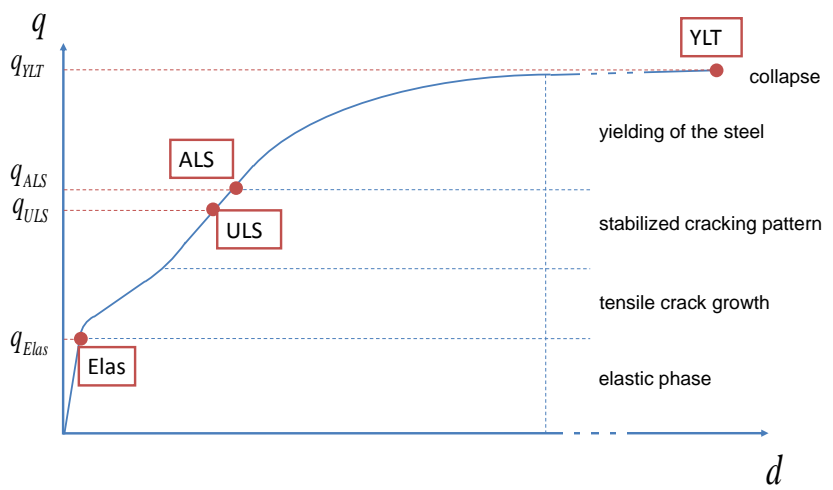

Fig. 3. Transitions between each damage level (Elas: elastic limit; ULS: ultimate limit state; ALS: accidental limit state; YLT: yield line theory).

The second (third) damage limit is attained when the bending moment defined by the ULS (ALS) is reached. In this case, the following assumptions are made:

- Sections remain planar during loading.

- No slip can occur between concrete and steel.

- The strain is linear along the thickness.

- Concrete's tensile strength is ignored $\left(f_{\mathrm{t}}=0\right)$.

- The ultimate compressive strain of the concrete $\left(\epsilon_{\mathrm{bc}}\right)$ and the ultimate tensile strain of the steel $\left(\epsilon_{\mathrm{uk}}\right)$ are limited to $3.5 \%$ and $10 \%$, respectively.

As functions of the ULS and the ALS, concrete and steel strengths change with the safety coefficients $\left(\gamma_{\mathrm{b}}\right.$ and $\left.\gamma_{\mathrm{s}}\right)$. As a consequence, the corresponding maximal bending moments also change. Figure 5 depicts assumed behaviors of the concrete and the steel.

The RC wall design consists in attaining the maximum strengths in concrete and in the steel at the same time. The compressive strength of concrete $f_{\mathrm{bc}}$ (Eq. 1) is estimated: no creep effect is taken into account $(\theta=0.85)$, and the safety coefficient $\gamma_{b}=1.15$. According to assumptions previously made, the Eurocode 2 supplies the coefficient $\mu_{\mathrm{AB}}=0.186$. Thus, knowing the effective depth of the RC cross section $d$, the corresponding moment per linear meter developed in the section can be calculated

$M_{\mathrm{AB}}=\mu_{\mathrm{AB}} d^{2} f_{\mathrm{bc}}$.

Next, by knowing the lever arm $z \approx 0.9 d$, the amount of steel (i.e., the percentage of steel inside concrete if normalized by the section area) needs to ensure that the balance of the bending moment is equal to

$A_{\mathrm{s}}=\frac{M_{\mathrm{AB}}}{z \frac{f_{y}}{\gamma_{\mathrm{s}}}}$, where $\gamma_{\mathrm{s}}=1.15$ for ULS. Finally, the ULS and ALS $\left(\gamma_{\mathrm{s}}=\right.$ 1.0) bending moments are expressed as

$M_{\mathrm{ULS}}=M_{\mathrm{AB}}$,
$M_{\mathrm{ALS}}=A_{\mathrm{s}} z \frac{f_{y}}{\gamma_{\mathrm{s}}}$.

\section{Boundary conditions}

When the $\mathrm{RC}$ wall is subjected to a uniform pressure, the spatial distribution of bending moments depends on the boundary conditions of each wall edge. Many combinations can be considered (free edge, clamped edge or simply supported edge). Bares (1969) proposed a useful abacus that gives the maximal bending moments developed in elastic rectangular plates for numerous configurations of boundary conditions.

In this paper, the derivation of vulnerability relations is carried out within a reliability framework. Thus, to calculate the failure probability of the $\mathrm{RC}$ wall, many runs are needed. By using the abacus to assess the RC wall's resistance capacity, the computational time to perform a single run is very low, which makes it possible to use robust but computationally intensive reliability methods such as Monte Carlo simulations. Ten boundary conditions were implemented ( 1 to 10 , cf. Table 2). A linear spline is fitted to extrapolate coefficients from available coefficients ( $\beta_{x}$ and $\beta_{y}$ ) provided by the abacus. Knowing the limit bending moment for each damage stage, the corresponding pressure is deduced for each direction $x$ and $y$ :

$\begin{aligned} q^{x} & =\frac{M}{\beta_{x} l_{x}^{2}}, \\ q^{y} & =\frac{M}{\beta_{y} l_{y}^{2}} .\end{aligned}$

\subsubsection{RC wall collapse (yield line theory)}

The ultimate resistance of RC slabs under uniformly distributed pressure can be derived from the classical yield line theory (Johansen, 1962). This theory provides the collapse mechanism of the RC wall. Under an external loading, cracks will develop to form a pattern of "yield lines" until a mechanism is formed. A yield line corresponds to a nearly straight line along which a plastic hinge has developed. To perform the yield line theory algorithm, the bending moment along yield lines needs to be calculated. The bending moment per unit length along those lines remained constant and equal to the moment calculated in Eq. (6). Indeed, as we are considering a uniform and equal reinforcement along the horizontal and vertical directions, the steadiness is verified. Then the energy balance between external and internal forces is calculated. According to the assumed yield line pattern, each adjacent plate can rotate. The plates rotate around axes defined by the edges of the slab and the yield lines. During the rotation, 


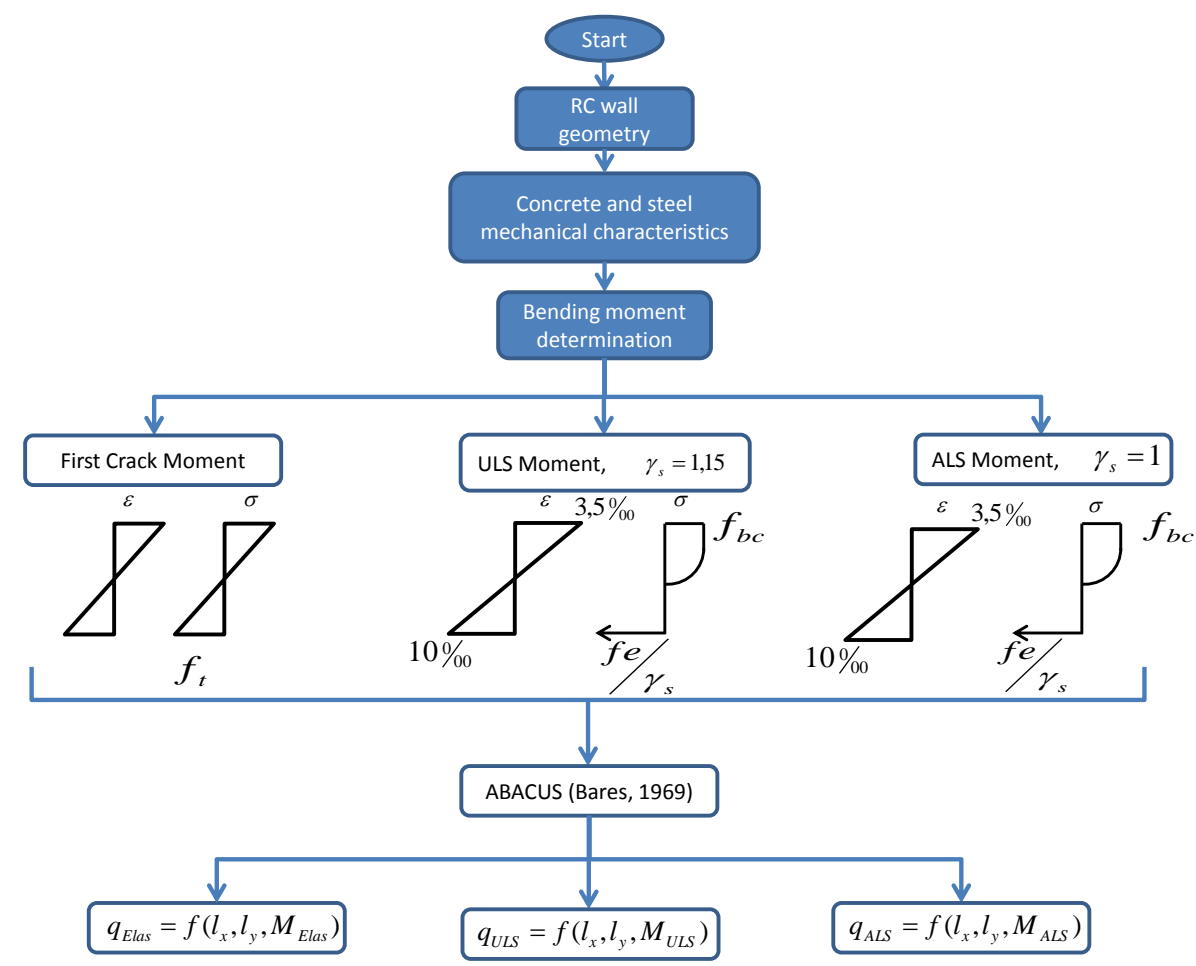

Fig. 4. Flowchart to calculate loading pressure related to each moment based on damage levels (Elas/ULS/ALS): first levels include geometry, mechanical characteristics and moment calculation; then, by inverting the Bares abacus (Bares, 1969), the corresponding loads are deduced.

(a)

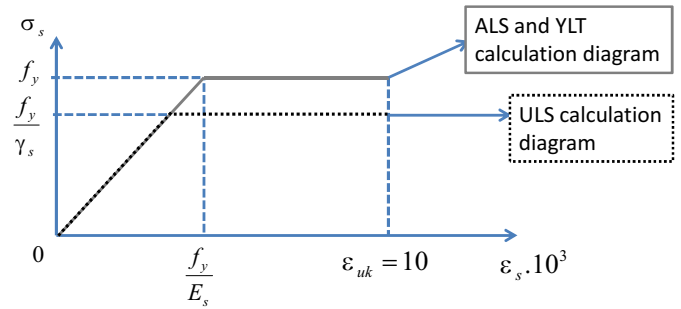

(b)

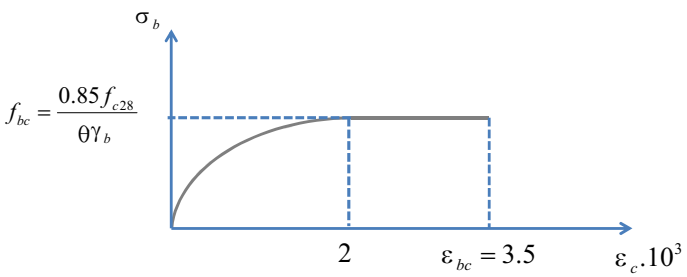

Fig. 5. Strain-stress calculation diagrams of the steel: perfect elasto-plastic grey diagram for the ALS and YLT calculations, black dotted line for the ULS calculation diagram where the steel yield strength is modified by the safety coefficient $\gamma_{\mathrm{s}}(\mathbf{a})$, and strain-stress calculation diagram of the concrete (b).

energy is dissipated inside the material by yielding. The dissipated energy is calculated as $M_{\mathrm{p}}^{i} \theta_{i} L_{i}$, where $M_{\mathrm{p}}^{i}$ is the plastic moment of the yield line considered $i, \theta_{i}$ the magnitude of the angle of rotation, and $L_{i}$ the length of the yield line.
The ultimate load is calculated from the equality between the external energy $\left(W_{\text {ext }}\right)$ and the internal energy $\left(W_{\text {int }}\right)$. In order to find the most likely collapse pattern, the kinematic theorem is used. It consists in determining the failure pattern minimizing the collapse load. Thus, the following equations are derived:

$\left\{\begin{array}{l}W_{\text {int }}=\sum_{i=1}^{n_{L}} \boldsymbol{M}_{\mathrm{p}}^{i} \cdot \boldsymbol{\theta}_{i} \cdot L_{i} \\ W_{\mathrm{ext}}=q \iint \delta(x, y) \mathrm{d} x \mathrm{~d} y\end{array}\right.$

where $n_{L}$ is the number of yield lines, $\delta(x, y)$ is the displacement field of the slab and $q$ is the uniform load applied on the slab. Various failure patterns were considered as functions of the boundary conditions (Fig. 6). For each boundary condition, two failure patterns are mainly observed (Fig. 6, col. 2 and 3). Each pattern depends on an angle $\alpha_{1}$ or $\alpha_{2}$ calculated in order to minimize the energy.

\subsection{Reliability framework}

The structure's safety cannot be assessed from a deterministic point of view because several properties of the system are uncertain. Thus, the study is performed in a reliability framework.

\subsubsection{Failure probability definition}

The failure probability $P_{\mathrm{f}}$ is defined as the probability for the resistance of the structure $r$ to be less than or equal to an 
Table 2. Maximum bending moment coefficients $\left(\beta_{x}, \beta_{y}\right)$ for a rectangular plate subjected to an uniform load. The Poisson's ratio $v=0.15$ and $\frac{l_{x}}{l_{y}}=0.5$.

\begin{tabular}{|c|c|c|}
\hline Boundary conditions & $\beta_{x}$ & $\beta_{y}$ \\
\hline (1) four simply supported edges & 0.0991 & 0.0079 \\
\hline $\begin{array}{l}\text { (2) simply supported on the two large edges } \\
\text { clamped on the two small edges }\end{array}$ & 0.0835 & 0.0088 \\
\hline $\begin{array}{l}\text { (3) simply supported on one large edge } \\
\text { clamped on the three other edges }\end{array}$ & 0.0550 & 0.0045 \\
\hline $\begin{array}{l}\text { (4) one free large edge } \\
\text { clamped on the three other edges }\end{array}$ & $-v \times \beta_{y}$ & 0.0268 \\
\hline $\begin{array}{l}\text { (5) one free large edge } \\
\text { simply supported on the three other edges }\end{array}$ & $-v \times \beta_{y}$ & 0.0575 \\
\hline $\begin{array}{l}\text { (6) clamped on one small edge } \\
\text { simply supported on the three other edges }\end{array}$ & 0.0908 & 0.0084 \\
\hline $\begin{array}{l}\text { (7) simply supported side by side } \\
\text { clamped on the two other edges }\end{array}$ & 0.0570 & 0.0040 \\
\hline (8) four clamped edges & 0.0405 & 0.0024 \\
\hline $\begin{array}{l}\text { (9) one free large edge/one clamped large edge } \\
\text { simply supported on the two small edges }\end{array}$ & $-v \times \beta_{y}$ & 0.0288 \\
\hline $\begin{array}{l}\text { (10) one free large edge/one simply supported large edge } \\
\text { clamped on the two small edges }\end{array}$ & $-v \times \beta_{y}$ & 0.0361 \\
\hline
\end{tabular}

event size $s$ :

$P_{\mathrm{f}}=P[r \leq s]=\int_{-\infty}^{s} f_{\mathrm{R}}(r) \mathrm{d} r$.

To solve Eq. (10), the probability density function of the resistance $f_{\mathrm{R}}(r)$ needs to be known. The Monte Carlo algorithm is used to generate data samples. It is robust but a time-consuming method. By randomly generating $N$ variables from the input probability distributions, $N$ mechanical runs can be performed. Thus, the probability density function of the response can be approximated by the Monte Carlo integral: $\hat{P}_{f}$. The central limit theorem provides a $(1-\alpha)$ asymptotic confidence interval reflecting a significance level of $\alpha$ :

$$
\begin{aligned}
& \hat{P}_{f}\left(1-z_{1-\alpha / 2} \frac{\sqrt{\hat{P}_{f}\left(1-\hat{P}_{f}\right)}}{\sqrt{N}}\right) \leq P_{f} \\
& \leq \hat{P}_{f}\left(1+z_{1-\alpha / 2} \frac{\sqrt{\hat{P}_{f}\left(1-\hat{P}_{f}\right)}}{\sqrt{N}}\right),
\end{aligned}
$$

where $z_{1-\alpha / 2}$ is the $\alpha$ quantile of the normal distribution.

\subsubsection{Sobol's index}

Sobol's index provides the contribution of inputs to model outputs. It consists in quantifying the contribution of each input variable to the entire system's variability. It is based on a variance sensitivity analysis (Sobol, 2001). Saltelli et al. (2010) provide different numerical estimates and a comparison between their efficiency. For independent input variables, Sobol's first-order sensitivity coefficient $S_{i}$ is equal to the total effect index $S_{\mathrm{T} i}$. Considering $Y$ as the model output and $X$ as the vector of inputs, Sobol's indices are defined as

$$
S_{i}=\frac{V_{X_{i}}\left(E_{X_{\sim i}}\left(Y \mid X_{i}\right)\right)}{V(Y)},
$$

$S_{T i}=1-\frac{V_{X_{\sim i}}\left(E_{X_{i}}\left(Y \mid X_{\sim i}\right)\right)}{V(Y)}$,

where $V$ is the variance and more particularly $V_{X_{i}}$ is the variance of the argument taken over $X_{i}, V_{X_{i}}\left(E_{X_{\sim i}}\left(Y \mid X_{i}\right)\right)$ is the expected reduction in variance that would be obtained if $X_{i}$ could be fixed. 


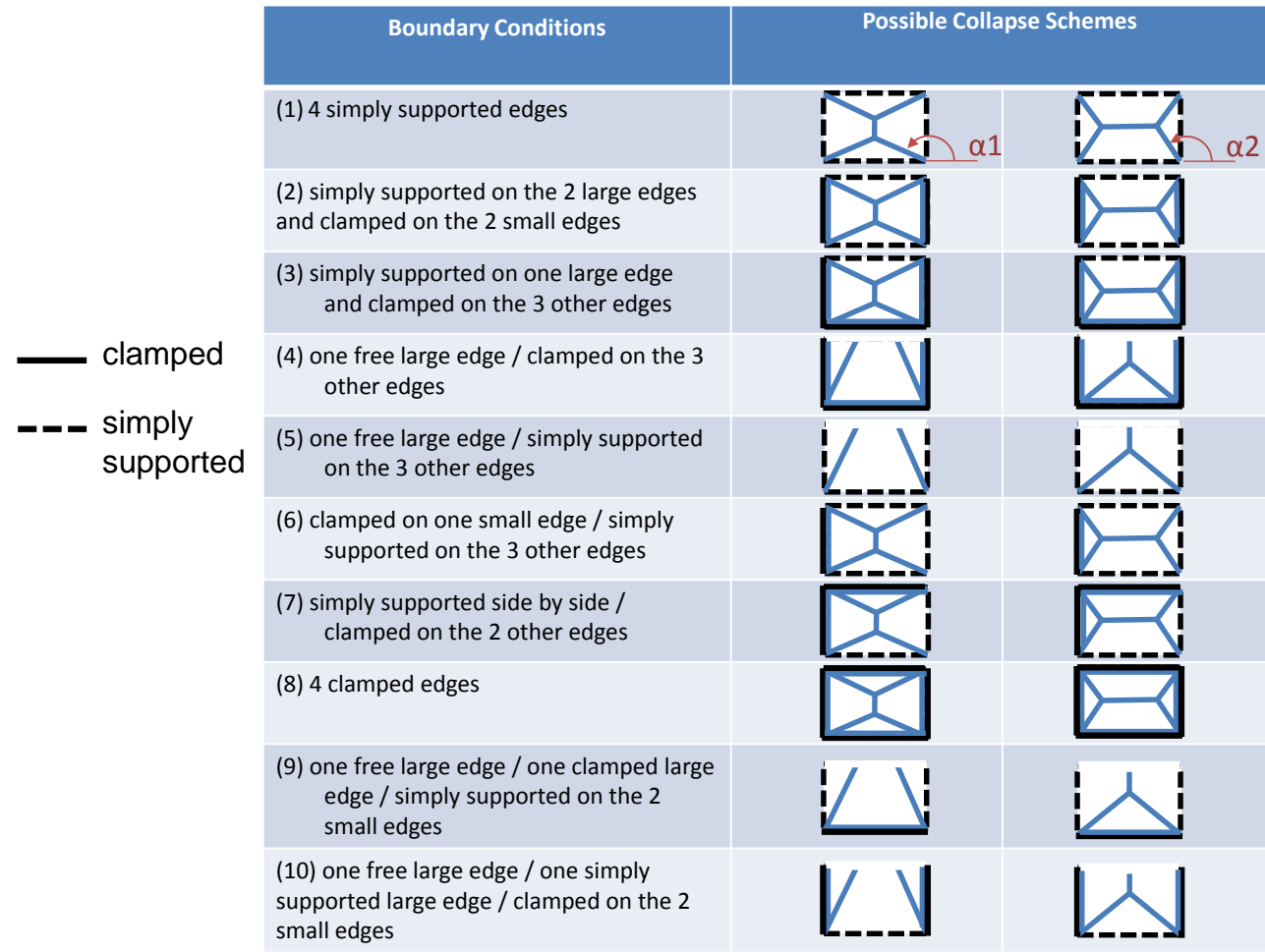

Fig. 6. Failure patterns according to several boundary conditions when considering yield line theory.

According to Saltelli et al. (2010), Jansen (1999) provides the most efficient estimator of Eq. (13) through the approximation

$\hat{S_{T i}}=\frac{1}{2 N} \sum_{j=1}^{N}\left(f(\mathbf{A})_{j}-f\left(\mathbf{A}_{B}^{(i)}\right)_{j}\right)^{2}$,

where $Y=f\left(X_{1}, X_{2}, \ldots, X_{k}\right), \mathbf{A}$ and $\mathbf{B}$ are an $N \times k$ matrix of input factors and $\mathbf{A}_{B}^{(i)}$ is a matrix where column $i$ comes from matrix $\mathbf{B}$ and all other $k-1$ columns from matrix $\mathbf{A}$.

\subsection{Vulnerability assessment}

Statistical distributions of inputs need to be defined. Here, six input variables were chosen and their distributions were determined: $l_{x}, l_{y}, h, f_{\mathrm{c} 28}, f_{y}$ and $f_{\mathrm{t}}$. Different sets of distributions are used: a set of normal independent distributions, a more realistic distribution provided by the Joint Committee on Structural Safety (2001) (JCSS) and intermediate cases. Thus, building cumulative distribution functions of mechanical capacity load outputs allows for fragility curves to be assessed.

\subsubsection{Statistical description of inputs}

\section{Normal distributions}

First, to analyze the effect of each variable separately, a normal distribution describes each variable. Low and Hao
Table 3. Distribution parameters of material inputs.

\begin{tabular}{lll}
\hline Variable & Mean & Standard deviation \\
\hline$l_{x}(\mathrm{~m})$ & 8.0 & 0.4 \\
$l_{y}(\mathrm{~m})$ & 4.0 & 0.2 \\
$h(\mathrm{~m})$ & 0.2 & 0.01 \\
$f_{\mathrm{c} 28}(\mathrm{MPa})$ & 30 & 1.5 \\
$f_{y}(\mathrm{MPa})$ & $500 \times 10^{6}$ & $25 \times 10^{6}$ \\
$f_{\mathrm{t}}(\mathrm{MPa})$ & 2 & 0.1 \\
\hline
\end{tabular}

(2001) provided several references identifying distributions for material inputs involved in a reinforced concrete slab problem. Mirza and MacGregor (1979) assumed normal distributions to model the variability/uncertainty regarding the sizes of slabs. After in situ experiments, a coefficient of variation of 0.05 is suggested and the designed value is adopted as the mean distribution value. To carry out a first statistical description of the proposed model, a coefficient of variation of 0.05 is assumed for all the inputs considered, leading to the means and standard deviations provided in Table 3.

\section{JCSS distributions}

As reported by the JCSS, correlations between input variables can be taken into account. Steel's yield strength is still independent and follows a normal distribution. On the other hand, the tensile strength $\left(f_{\mathrm{t}}\right)$ and the compressive strength 
Table 4. Table presenting the marginal distributions of independent material inputs for the JCSS distribution case. Other inputs are computed according to Eqs. (15), (16) and (17) of Sect. 2.4.1.

\begin{tabular}{lll}
\hline Variable & Mean & Standard deviation \\
\hline$l_{x}(\mathrm{~m})$ & 8.0 & 0.4 \\
$l_{y}(\mathrm{~m})$ & 4.0 & 0.2 \\
$h(\mathrm{~m})$ & 0.2 & 0.01 \\
$f_{y}(\mathrm{MPa})$ & $560 \times 10^{6}$ & $30 \times 10^{6}$ \\
\hline
\end{tabular}

of the concrete $\left(f_{\mathrm{bc}}\right)$ distributions are deduced from the basic concrete compression strength $\left(f_{\mathrm{c} 28}\right)$ distributions. For a ready-mixed concrete type with a $C 25$ concrete grade, based on the given parameters, the values of $m, v, s, n$ are $m=3.65, v=3.0, s=0.12$ and $n=10$, and $t_{v}$ is a random variable from a Student distribution for $v$ degrees of freedom:

$f_{\mathrm{c} 28}=\exp \left(m+t_{v} s\left(1+\frac{1}{n}\right)^{0.5}\right)$.

Then, $f_{t}$ and $f_{\mathrm{bc}}$ are calculated with $\lambda, Y_{1}$ and, $Y_{2} . \lambda$ is a factor taking into account the systematic variation of in situ compressive strength and the strength from standard tests. Finally, $\left(Y_{i}\right)_{i=1,2}$ are lognormal variables representing additional variations due to special placing, curing, and hardening of the concrete. In our case, $\alpha_{c}$ is considered equal to $\frac{0.85}{\theta \gamma_{b}}$ :

$f_{\mathrm{bc}}=\alpha_{c} f_{\mathrm{c} 28}^{\lambda} Y_{1}$,

$f_{t}=0.3 f_{\mathrm{bc}}^{2 / 3} Y_{2}$.

For all parameters, the marginal mean and standard deviation were set according to the JCSS recommendation (Table 4). Difference with the previous case (Table 3$)$ concerns $\left(f_{\mathrm{c} 28}\right)$ for which they are higher in this case.

\section{Intermediate distributions}

To bridge the gap between the realistic JCSS distributions case and the normal independent choice, seven intermediate distributions were considered, differing from each other in terms of distribution type and/or covariance matrix:

- A lognormal distribution for three multiplicative variables: the tensile strength and the compressive strength of concrete, and the steel yield strength with parameters of Table 5. Means and standard deviations are the same as for the normal case.

- A lognormal distribution for the tensile strength and the compressive strength of concrete, and the steel yield strength with parameters of Table 6. Means and standard deviations are the same as for the JCSS case.
Table 5. Table presenting the marginal lognormal distributions used for the tensile strength and the compressive strength of concrete, as well as the steel yield strength. Means and standard deviations are the same as in Table 3 . The parameters $\mu_{\mathrm{LN}}$ and $\sigma_{\mathrm{LN}}$ are the resulting parameters of the lognormal distributions.

\begin{tabular}{lrrrr}
\hline Variable & Mean & $\begin{array}{r}\text { Standard } \\
\text { deviation }\end{array}$ & $\mu_{\mathrm{LN}}$ & $\sigma_{\mathrm{LN}}$ \\
\hline$f_{\mathrm{t}}(\mathrm{MPa})$ & 2 & 0.1 & 0.69 & 0.05 \\
$f_{\mathrm{c} 28}(\mathrm{MPa})$ & 30 & 1.5 & 3.40 & 0.05 \\
$f_{y}(\mathrm{MPa})$ & $500 \times 10^{6}$ & $25 \times 10^{6}$ & 20.03 & 0.05 \\
\hline
\end{tabular}

Table 6. Marginal JCSS-based lognormal distributions used for the tensile strength and the compressive strength of concrete, as well as the steel yield strength.

\begin{tabular}{lrrrr}
\hline Variable & Mean & $\begin{array}{r}\text { Standard } \\
\text { deviation }\end{array}$ & $\mu_{\mathrm{LN}}$ & $\sigma_{\mathrm{LN}}$ \\
\hline$f_{\mathrm{t}}(\mathrm{MPa})$ & 2.38 & 0.76 & 0.82 & 0.31 \\
$f_{\mathrm{c} 28}(\mathrm{MPa})$ & 38.9 & 6.11 & 3.65 & 0.16 \\
$f_{y}(\mathrm{MPa})$ & $560 \times 10^{6}$ & $30 \times 10^{6}$ & 20.14 & 0.053 \\
\hline
\end{tabular}

- A lognormal distribution for the tensile strength and the compressive strength of concrete, and the steel yield strength. According to the Table 6, standard deviations are multiplied by 2 to emphasize lognormal distributions asymmetry.

- A normal joint distributions for all the variables with variance-covariance matrix deduced from the JCSS distributions and the means from Table 3.

- A normal joint distribution for the six parameters $l_{x}$, $l_{y}, h, f_{\mathrm{c} 28}, f_{y}$ and $f_{\mathrm{t}}$ using mean and standard deviation from Table 3 and correlation coefficients (covariance) of the JCSS case. The main correlation is the relation between $f_{\mathrm{c} 28}$ and $f_{\mathrm{t}}: \rho\left(f_{\mathrm{c} 28}, f_{\mathrm{t}}\right)=0.31$; others are lower than 0:01, i.e., close to independence.

- A normal joint distribution for the six parameters $l_{x}$, $l_{y}, h, f_{\mathrm{c} 28}, f_{y}$ and $f_{\mathrm{t}}$ using mean, standard deviation and correlation coefficients (covariance) of the JCSS case.

- Uncorrelated JCSS distributions: to assess the effect of correlation on the JCSS case, each modeled variable was selected independently to break down dependencies.

\subsubsection{Fragility curves derivation}

A fragility curve $F(x)$ is a monotonic curve providing a failure probability as a function of the magnitude of a loading, here a pressure applied, hence the cumulative distribution function $F(x)$ of the failure probability for the load $x$. The 
(a)

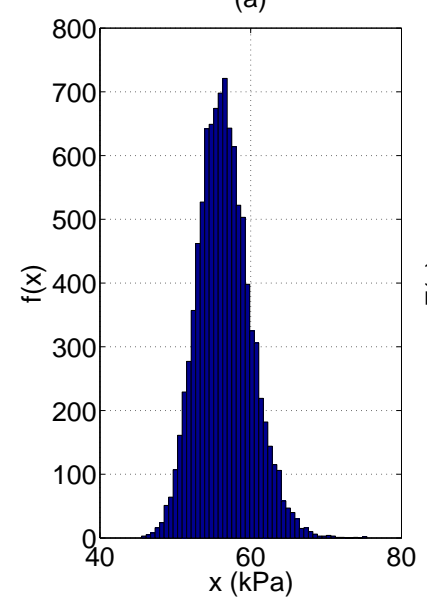

(b)

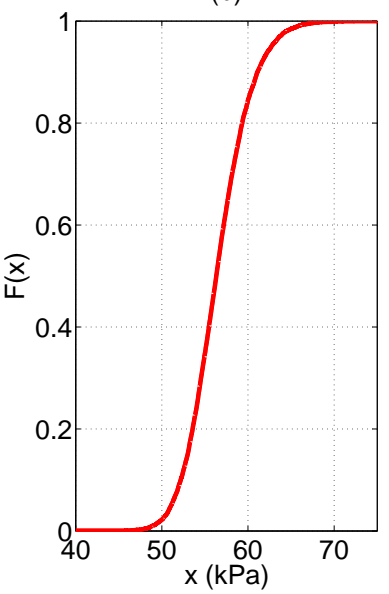

Fig. 7. Output histogram of the ULS case for a rectangular wall with one free edge and three clamped edges with normal independent inputs (a), and the cumulative distribution function associated (b).

usual way to compute fragility curves is to set a pressure and vary the inputs from their statistical distributions. Thus, for each pressure a failure probability is obtained to build the fragility curve. In this paper, the approach is somewhat original because failure probabilities are derived from an inverse resolution. First, the structure capacity of resistance is found; then, by abacus inversion, a load distribution is assessed. Finally, the cumulative distribution function of the latter distribution makes it possible to link a failure probability to a pressure. As an example, Fig. 7 depicts an output histogram of the ULS case for a rectangular wall with one free edge and three clamped edges with normal independent inputs and the fragility curve associated through its cumulative distribution function.

\section{Results}

\subsection{Fragility curves with uncorrelated normally distributed inputs}

\subsubsection{Overview of all configurations}

Using 10000 runs per curve, smooth fragility curves are obtained. Figure 8 depicts fragility curves according to explored boundary conditions. They are sorted by the four failure criteria. Two visual groups are formed. First, all the curves representing the elastic limit state are gathered at low pressure loads. By considering the minimum $2.5 \%$ quantile and their maximum $97.5 \%$ quantile, their fragility range is $[2.8,27.2]$ $(\mathrm{kPa})$. They do not interfere with fragility curves of the other failure criteria. On the other hand, the ULS, ALS and YLT fragility curves are defined on a range from $22.7 \mathrm{kPa}$ to $218.6 \mathrm{kPa}$. It is interesting to note that the ALS fragility

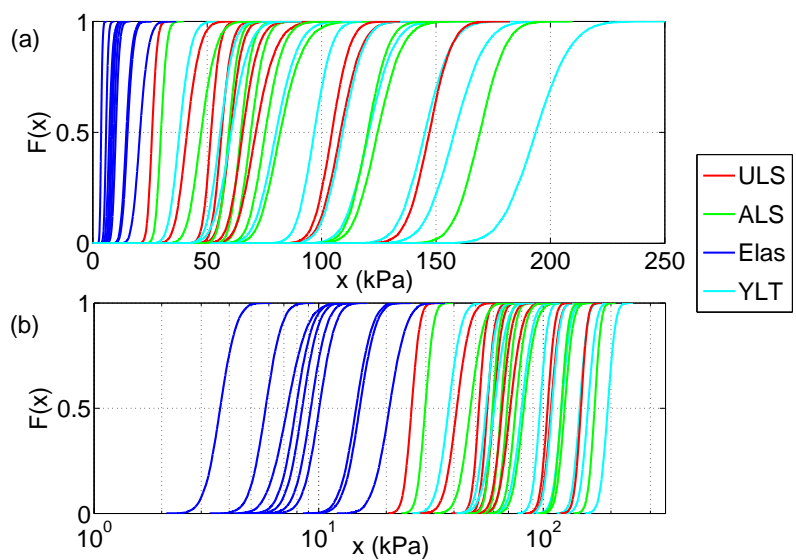

Fig. 8. Fragility curves according to boundary conditions sorted by failure criterion: (a) linear frame and (b) semi-log frame.

curves are scaled from the ULS curves by the safety factor 1.15. This is easily explained by the definition itself of the ALS failure criterion.

Another point of view can be taken by plotting the same data according to the description of their boundary conditions (Fig. 9). Sets of fragility curves can be deduced. The four weakest structures present free edges. Rectangular walls with one free edge are sorted from the weakest by their boundary conditions as below: (1) one free edge and three supported edges; (2) one supported edge, two clamped edges and one free; (3) one clamped edge, two supported edges and one free*; and (4) one free edge and three clamped edges (*exception for the YLT limit state where 3 and 4 are exchanged). Then the second set of curves gathers the rectangular wall with supported edges ((5) four supported edges, (6) one clamped edge and three supported ones, (7) two supported edges and two clamped ones, (8) two supported edges and two clamped edges side by side, and (9) one supported edge and three clamped ones). Finally, the less vulnerable rectangular wall has four clamped edges.

Equation (18) provides the $p$ quantile of each vulnerability curve:

$F(x)=\operatorname{Pr}(X \leq x)=p$.

The previous equation allows considering a more quantitative approach. Table 7 sums up the $50 \%$ quantiles and similar conclusions as described above are set up. The fragility range is defined as an interval: the lower bound is the $2.5 \%$ quantile and the upper bound is the $97.5 \%$ quantile of the fragility curve, which could be considered as very useful quantitative thresholds for engineering applications.

\subsubsection{An example: one free edge and three clamped edges}

To investigate Monte Carlo confidence interval quantification, a focus on a particular case was required. The selected 
Table 7. The $50 \%$ quantile of the CDF fragility curves according to boundary conditions and failure criterion, and (2.5\%, $97.5 \%)$ quantile defining a fragility range $(\mathrm{kPa})$.

\begin{tabular}{|c|c|c|c|c|}
\hline Boundary conditions & Elas & ULS & ALS & YLT \\
\hline (1) four simply supported edges & $\begin{array}{c}8.4 \\
(6.5,10.9)\end{array}$ & $\begin{array}{c}60.2 \\
(52.3,69.1)\end{array}$ & $\begin{array}{c}69.3 \\
(60.2,79.5)\end{array}$ & $\begin{array}{c}97.0 \\
(85.5,109.5)\end{array}$ \\
\hline $\begin{array}{l}\text { (2) simply supported on the two large edges } \\
\text { clamped on the two small edges }\end{array}$ & $\begin{array}{c}10.0 \\
(7.7,13.0)\end{array}$ & $\begin{array}{c}71.6 \\
(59.4,87.6)\end{array}$ & $\begin{array}{c}82.4 \\
(68.3,100.7)\end{array}$ & $\begin{array}{c}121.0 \\
(104.8,139.1)\end{array}$ \\
\hline $\begin{array}{l}\text { (3) simply supported on one large edge } \\
\text { clamped on the three other edges }\end{array}$ & $\begin{array}{c}15.2 \\
(11.6,19.7)\end{array}$ & $\begin{array}{c}108.6 \\
(95.0,124.2)\end{array}$ & $\begin{array}{c}124.9 \\
(109.3,142.8)\end{array}$ & $\begin{array}{c}158.5 \\
(138.8,180.2)\end{array}$ \\
\hline $\begin{array}{l}\text { (4) one free large edge } \\
\text { clamped on the three other edges }\end{array}$ & $\begin{array}{c}7.8 \\
(6.0,10.3)\end{array}$ & $\begin{array}{c}56.0 \\
(49.9,63.7)\end{array}$ & $\begin{array}{c}64.4 \\
(57.4,73.2)\end{array}$ & $\begin{array}{c}80.5 \\
(66.6,96.7)\end{array}$ \\
\hline $\begin{array}{l}\text { (5) one free large edge } \\
\text { simply supported on the three other edges }\end{array}$ & $\begin{array}{c}3.6 \\
(2.8,4.7)\end{array}$ & $\begin{array}{c}26.0 \\
(22.7,29.6)\end{array}$ & $\begin{array}{c}29.9 \\
(26.1,34.1)\end{array}$ & $\begin{array}{c}38.1 \\
(30.9,46.7)\end{array}$ \\
\hline $\begin{array}{l}\text { (6) clamped on one small edge } \\
\text { simply supported on the three other edges }\end{array}$ & $\begin{array}{c}9.2 \\
(7.1,11.9)\end{array}$ & $\begin{array}{c}65.8 \\
(56.0,77.6)\end{array}$ & $\begin{array}{c}75.7 \\
(64.4,89.2)\end{array}$ & $\begin{array}{c}109.5 \\
(95.6,124.7)\end{array}$ \\
\hline $\begin{array}{l}\text { (7) simply supported side by side } \\
\text { clamped on the two other edges }\end{array}$ & $\begin{array}{c}14.6 \\
(11.2,19.2)\end{array}$ & $\begin{array}{c}104.7 \\
(93.1,117.6)\end{array}$ & $\begin{array}{c}120.4 \\
(107.1,135.3)\end{array}$ & $\begin{array}{c}145.5 \\
(128.3,164.4)\end{array}$ \\
\hline (8) four clamped edges & $\begin{array}{c}20.7 \\
(15.6,27.5)\end{array}$ & $\begin{array}{c}147.9 \\
(133.3,163.4)\end{array}$ & $\begin{array}{c}170.0 \\
(153.3,187.9)\end{array}$ & $\begin{array}{c}194.0 \\
(171.1,219.2)\end{array}$ \\
\hline $\begin{array}{l}\text { (9) one free large edge / one clamped large edge } \\
\text { simply supported on the two small edges }\end{array}$ & $\begin{array}{c}7.2 \\
(5.3,10.3)\end{array}$ & $\begin{array}{c}51.9 \\
(43.2,58.9)\end{array}$ & $\begin{array}{c}59.7 \\
(53.2,67.8)\end{array}$ & $\begin{array}{c}55.9 \\
(47.2,65.8)\end{array}$ \\
\hline $\begin{array}{l}\text { (10) one free large edge / one simply supported large edge } \\
\text { clamped on the two small edges }\end{array}$ & $\begin{array}{c}5.8 \\
(4.4,7.5)\end{array}$ & $\begin{array}{c}41.4 \\
(33.5,50.8)\end{array}$ & $\begin{array}{c}47.6 \\
(38.5,58.5)\end{array}$ & $\begin{array}{c}60.9 \\
(48.9,74.1)\end{array}$ \\
\hline
\end{tabular}

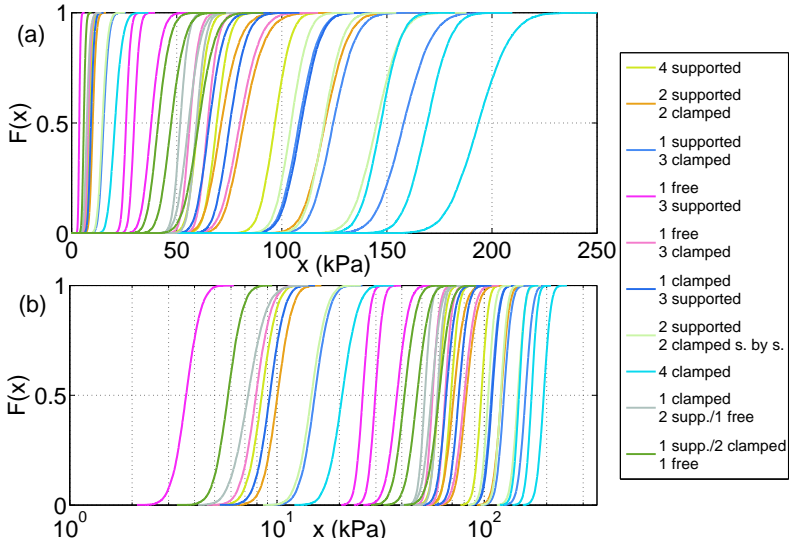

Fig. 9. Fragility curves according to boundary conditions sorted by boundary conditions: (a) linear frame and (b) semi-log frame.

case is the rectangular wall with one free edge and three clamped edges (Fig. 10). The four limit state fragility curves can be distinguished together with Monte Carlo confidence intervals. As mechanical runs are not time-consuming, the number of calls $N$ can be high enough to make numerical uncertainty negligible. Thus 10000 runs induce thin confidence intervals near the curve, giving confidence in all the numerical results provided.

\subsection{Parametric study}

This section is devoted to the analysis of total Sobol indices. As each of the input variables is independent, their sum is equal to 1 . Sensitivity pie charts of outputs according to the input distribution can be plotted (Fig. 11). Four input parameters influence the fragility assessment based on the elastic failure criterion: $f_{\mathrm{t}}, l_{x}, l_{y}$ and $h$. The variable $h$ is the predominant variable affecting the elastic-based failure probability. The ULS and ALS have the same sensitivity pie charts. Three input parameters are involved in the variability of ULS- and ALS-based failure probabilities: $l_{x}, l_{y}$ and $f_{\mathrm{c} 28}$. $f_{\mathrm{c} 28}$ seems to be the variable influenced the most by these outputs. This indicates which variables should be considered with the greatest care while designing a structure in practice, depending on the chosen failure criterion.

\subsection{Sensitivity to input distributions choice}

Fragility curves are highly dependent on the input distributions used. Outcomes were obtained from the two first distributions previously described (Fig. 12). As a general overview, more elaborated distributions induce greater 
Table 8. Quantiles of fragility curves illustrated in Fig. 13.

\begin{tabular}{|c|c|c|c|c|}
\hline Approach & $Q_{2.5 \%}$ & $Q_{50} \%$ & $Q_{97.5 \%}$ & $Q_{97.5 \%}-Q_{2.5} \%$ \\
\hline Deterministic & & 55.5 & & 0 \\
\hline JCSS & 44.9 & 62.4 & 86.8 & 41.9 \\
\hline JCSS independent & 45.3 & 62.6 & 86.8 & 41.6 \\
\hline Normal independent & 50.2 & 56.3 & 64.3 & 14.1 \\
\hline Correlated normal & 50.3 & 56.3 & 64.0 & 13.6 \\
\hline Normal, correlation and variance from JCSS case & 33.7 & 56.6 & 79.4 & 45.7 \\
\hline Lognormal, mean and variance from normal case & 51.3 & 56.2 & 63.6 & 12.3 \\
\hline Normal, correlation, variance and mean from JCSS case & 42.8 & 63.3 & 84.5 & 41.7 \\
\hline Lognormal, mean and variance from JCSS case & 45.2 & 62.4 & 86.2 & 41.0 \\
\hline Lognormal, mean and variance $(\times 4)$ from JCSS case & 32.0 & 60.3 & 114.6 & 82.6 \\
\hline
\end{tabular}

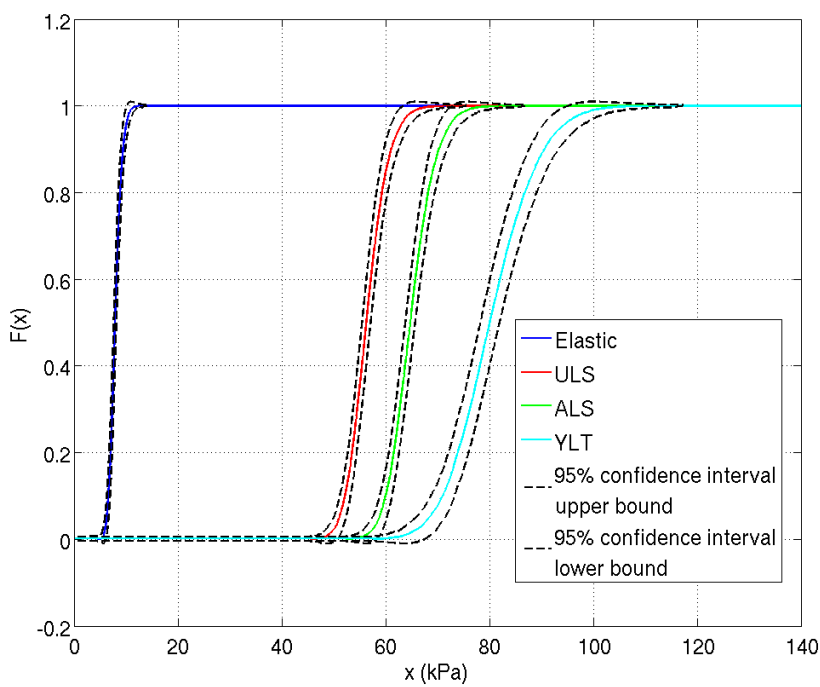

Fig. 10. Vulnerability curves and their $95 \%$ confidence intervals from Monte Carlo simulations of a slab with one free edge and three clamped edges.

spread in fragility curves. Their fragility ranges have a higher amplitude than the range derived from independent normal approaches. One explanation is that taking into account correlations makes certain "extreme" combinations of inputs more likely than in the independent case. Another explanation lies in the number of variables considered: the more numerous they are, the more uncertainties are taken into account, and also the larger the fragility range of the fragility curves is.

To ascertain and detail this conclusion, Fig. 13 focuses on the ULS example for the same boundary conditions. It appears clearly that, from the deterministic point of view (a simple 0-1 response if the fragility limit is attained or is not attained) to the JCSS-based approach, fragility curves have wider fragility ranges. Quantiles at $2.5 \%, 50 \%$ and $97.5 \%$ support these results (Table 8 ). Note, however, that the more complex case (i.e., the JCSS case), despite its wider spread, shows higher (and thus "safer") modal values, and therefore simpler approaches (normal or lognormal inputs) can be used in practice, at least as first approximations.

The $50 \%$ quantile depends nearly only on the means of the three material parameters $f_{y}, f_{\mathrm{c} 28}$ and $f_{\mathrm{t}}$. Indeed, the $50 \%$ quantile remains fully constant to $\sim 56 \mathrm{kPa}$ regardless of the covariance matrix for Gaussian inputs with $f_{y}, f_{\mathrm{c} 28}$ and $f_{\mathrm{t}}$ centered on their nominal values $500.10^{6}$, 30 and $2 \mathrm{MPa}$, respectively. Switching to the JCSS leads to a higher $50 \%$ quantile $\sim 62 \mathrm{kPa}$ independent of the correlation structure. In addition, the $50 \%$ quantile remains nearly unchanged with independent lognormally distributed inputs with the same mean even if these, by definition, introduce non-symmetry into the problem. This asymmetry effect is, however, visible when the standard deviation is multiplied by 2 . By the way, the fragility range is logically also increased (Table 8 )

All in all, the fragility range and fragility curves shape changes mainly according to the marginal variances, much higher in the different JCSS cases, with covariance between the different inputs and marginal distribution types having less influence.

\section{Conclusions}

The proposed approach can be considered as a comprehensive framework providing fragility curves for RC walls exposed to a snow avalanche pressure load. It could be considered with benefits for other sorts of problems and in particular for other types of civil engineering structures (structures with different materials, structures built using another technology, etc.) or natural hazards.

In detail, the influence of the boundary conditions and of the stochastic input distributions were systematically investigated, so as to provide robust fragility curves for various building types. Their most useful application may be individual risk assessment, including sensitivity analyses, for which the main concern is to evaluate the survival probability as a function of space for a hypothetical individual within different building types. 


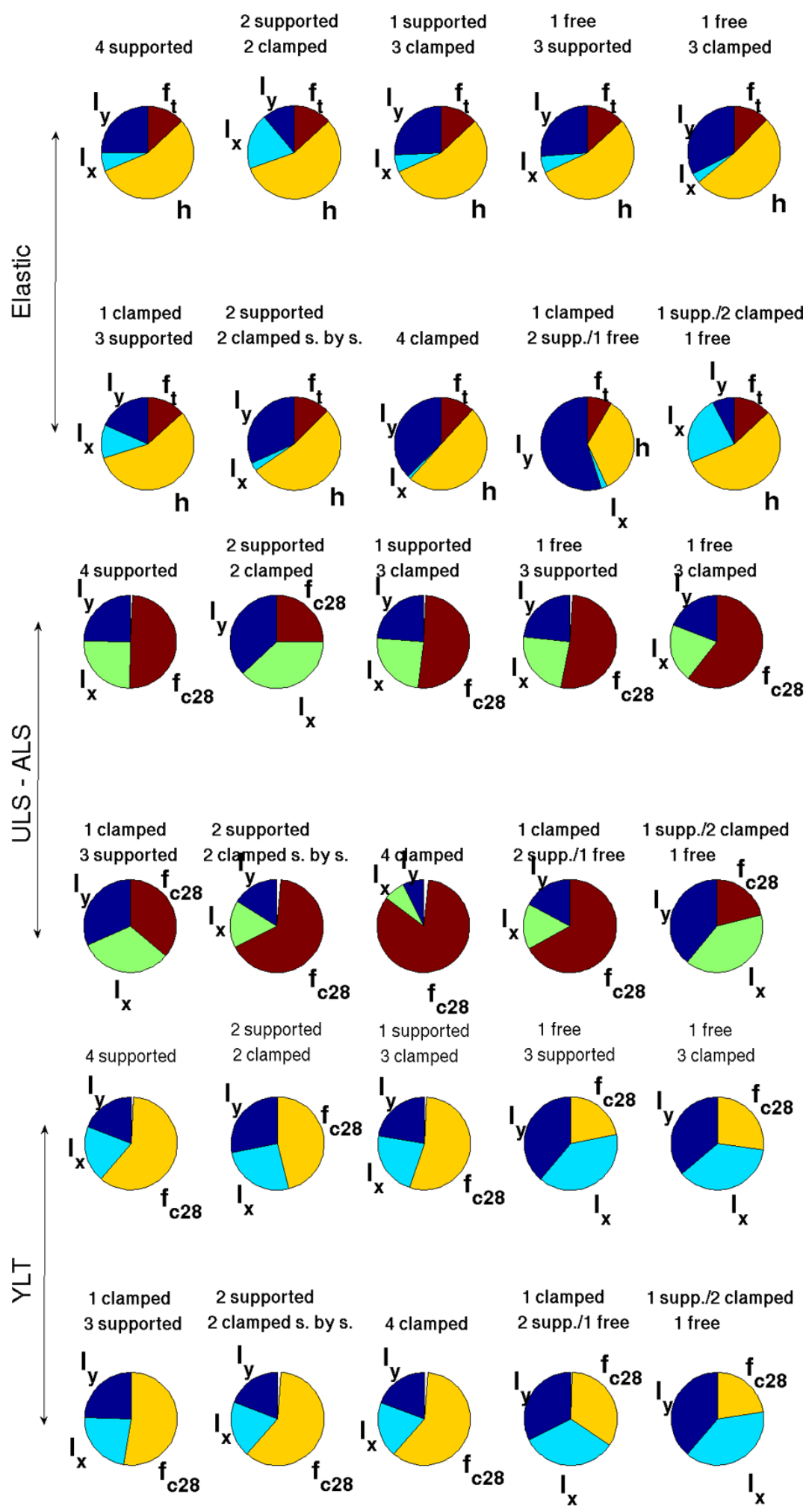

Fig. 11. Sensitivity pie charts for the elastic, ULS (ALS) and YLT failure criteria. 


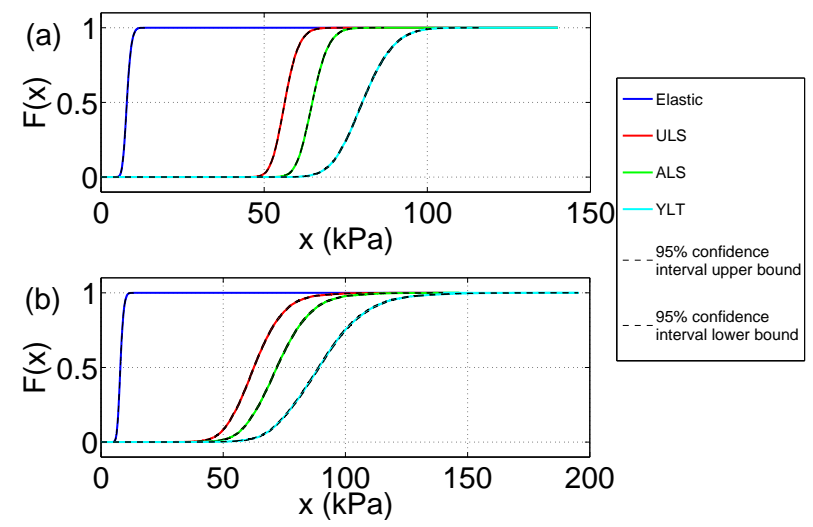

Fig. 12. Comparison of fragility curves from different input distributions of a slab with one free edge and three clamped edges: (a) normal independent distributions, (b) JCSS distribution.

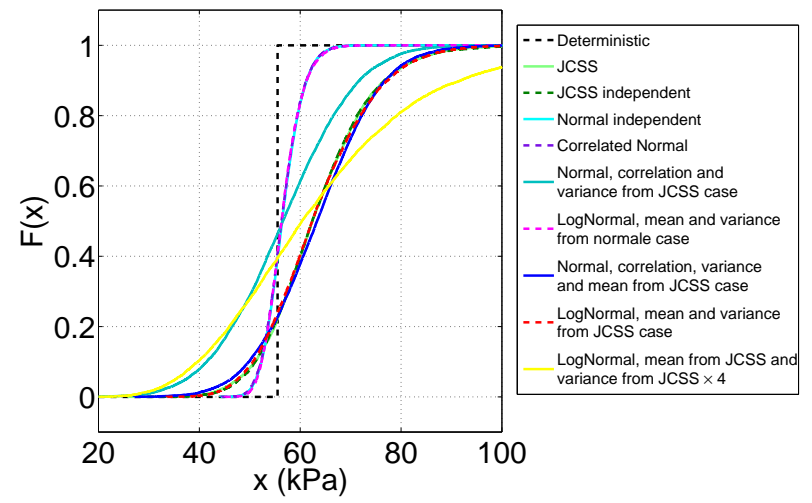

Fig. 13. Comparison between a deterministic approach and fragility curves computed with different input distributions. Fragility curves are here calculated for a slab with one free edge and three clamped edges under ULS considerations.

Four limit states based on the RC wall's mechanical response were considered: three local (cross-section scale) and one global (wall scale). For instance, the distinction between the ULS, concerning the safety of people, and the real collapse, where the structure is no longer standing, could lead to considering different thresholds for risk boundary assessment, leading to refined risk maps taking into account the winter usage of each building.

It has also been shown that, from a statistical point of view, stochastic input distributions strongly influence the shape of the fragility curves. Hence, mean and standard deviation of each variable, independent or correlated variables as well as the number of variables considered, constitute important factors in the variability of fragility curves. This sensitivity to the input parameter distributions highlights that it seems important to consider and describe precisely the uncertainty sources for each application.
The deterministic simulations were carried out through simplified and effective mechanical models in terms of CPU time. This allowed using the Monte Carlo method, which gave robust results for the failure probability assessment. Probabilistic input distributions are provided by the literature, but no statistical inference has been performed. Future work should therefore take real data into consideration and a Bayesian approach could then be appropriate to update the information conveyed by numerical simulations (Eckert et al., 2009).

Finally, it should be noted that more sophisticated mechanical models for civil engineering structures exist, based on the finite-element (FE) method, which can simulate the structure in greater detail and in particular describe how the damage field evolves when material nonlinearities develop inside the concrete and the steel reinforcement. However, these FE models are often more complex (i.e., in term of convergence) and time-consuming. Hence, they may be less well adapted to a generic individual risk base approach, but more useful for studies deriving refined fragility curves for specific structures included in precise engineering projects.

Acknowledgements. The authors thank the ANR research program MOPERA (Modélisation probabiliste pour l'Etude du Risque d'Avalanche - avalanches.irstea.fr/mopera-projet/) and the MAP3 ALCOTRA INTERREG program for financially supporting this work. The authors are also grateful to Regis Monnard for fruitful discussions. We also thank Dr. Lasaponara (handling editor) and the two anonymous referees for their constructive comments used to improve the paper.

Edited by: R. Lasaponara

Reviewed by: three anonymous referees

\section{References}

Arnalds, D., Jonasson, K., and Sigurdsson, S.: Avalanche hazard zoning in Iceland based on individual risk, Ann. Glaciol., 38, 285-290, International Symposium on Snow and Avalanches, Davos, Switzerland, 2004.

Barbolini, M., Cappabianca, F., and Sailer, R.: Empirical estimate of vulnerability relations for use in snow avalanche risk assessment, Management Information Systems, 9, 533-542, 4th International Conference on Computer Simulation in Risk Analysis and Hazard Mitigation, Rhodes, Greece, 2004.

Bares, R.: Tables pour le calcul des dalles et des parois, Dunod, Paris (French), 1969.

Baroudi, D., Sovilla, B., and Thibert, E.: Effects of flow regime and sensor geometry on snow avalanche impact-pressure measurements, J. Glaciol., 57, 277-288, 2011.

Bertrand, D., Naaim, M., and Brun, M.: Physical vulnerability of reinforced concrete buildings impacted by snow avalanches, Nat. Hazards Earth Syst. Sci., 10, 1531-1545, doi:10.5194/nhess-101531-2010, 2010.

Cappabianca, F., Barbolini, M., and Natale, L.: Snow avalanche risk assessment and mapping: A new method based on a combina- 
tion of statistical analysis, avalanche dynamics simulation and empirically-based vulnerability relations integrated in a GIS platform, Cold Regions Sci. Technol., 54, 193-205, 2008.

Committee, C. T.: Eurocode 2: Design of concrete structures Part:1-1 - general rules and rules for buildings (EN 1992-11:2004), 2004.

Daudon, D., Baroth, J., Ma, Y., Perrotin, P., and Mommessin, M.: Sensitivity of a reinforced concrete protective gallery under a snow avalanche load, Struct. Safety, 41, 47-56, 2013.

Eckert, N., Parent, E., Faug, T., and Naaim, M.: Optimal design under uncertainty of a passive defense structure against snow avalanches: from a general Bayesian framework to a simple analytical model, Nat. Hazards Earth Syst. Sci., 8, 1067-1081, doi:10.5194/nhess-8-1067-2008, 2008.

Eckert, N., Parent, E., Faug, T., and Naaim, M.: Bayesian optimal design of an avalanche dam using a multivariate numerical avalanche model, Stoch. Environ. Res. Risk Assess., 23, 11231141, 2009.

Eckert, N., Naaim, M., and Parent, E.: Long-term avalanche hazard assessment with a Bayesian depth-averaged propagation model, J. Glaciol., 56, 563-586, 2010.

Eckert, N., Keylock, C., Bertrand, D., Parent, E., Faug, T., Favier, P., and Naaim, M.: Quantitative risk and optimal design approaches in the snow avalanche field: Review and extensions, Cold Region. Sci. Technol., 79-80, 1-19, 2012.

Ellingwood, B. R.: Earthquake risk assessment of building structures, Reliability Eng. Syst. Safety, 74, 251-262, 2001.

Faug, T., Chanut, B., Beguin, R., Naaim, M., Thibert, E., and Baroudi, D.: A simple analytical model for pressure on obstacles induced by snow avalanches, Ann. Glaciol., 51, -8, 2010.

Favre, R., Jaccoud, J., Burdet, O., and Charif, H.: Dimensionnement des structure en bâton - Aptitude au service et élements de structures, Presses Polytech. et Univ. Romandes, 1990.

Fuchs, S., Thoeni, M., McAlpin, M. C., Gruber, U., and Bruendl, M.: Avalanche hazard mitigation strategies assessed by cost effectiveness analyses and cost benefit analyses - evidence from Davos, Switzerland, Nat. Hazards, 41, 113-129, 2007.

Givry, M. and Perfettini, P.: Construire en montagne : la prise en compte du risque d'avalanche (French), Tech. rep., Ministre de l'Écologie et du d'eveloppement durable, 2004.

Jansen, M.: Analysis of variance designs for model output, Computer Physics Communications, 117, 35-43, 1999.

Johansen, K.: Yield Line Theory, Cement and Concrete Association, London, UK, 1962.

Joint Committee on Structural Safety, J.: Probabilistic Model Code, Part I-III, available at: http://www.jcss.byg.dtu.dk/ (last access: 13 March 2014), 2001.

Jonasson, K., Sigurosson, S. T., and Arnalds, D.: Estimation of avalanche risk, Report No. R99001-URO, Reykjavik, Veourstofu Islands, 1999.

Keylock, C.: An alternative form for the statistical distribution of extreme avalanche runout distances, Cold Region. Sci. Technol., 42, 185-193, 2005.

Keylock, C. and Barbolini, M.: Snow avalanche impact pressure Vulnerability relations for use in risk assessment, Can. Geotech. J., 38, 227-238, 2001.
Lagaros, N. D.: Probabilistic fragility analysis: A tool for assessing design rules of RC buildings, Earthq. Eng. Eng. Vibration, 7, 4556, 2008.

Lemaire, M.: Fiabilité des structures - Couplage mécano-fiabiliste statique, Paris: Hermès - Lavoisier, 2005.

Li, Y. and Ellingwood, B. R.: Reliability of woodframe residential construction subjected to earthquakes, Struct. Safety, 29, 294 307, probabilistic Concepts in the Design of Timber Structures, 2007.

Low, H. Y. and Hao, H.: Reliability analysis of reinforced concrete slabs under explosive loading, Struct. Safety, 23, 157-178, 2001.

Mavrouli, O. and Corominas, J.: Rockfall vulnerability assessment for reinforced concrete buildings, Nat. Hazards Earth Syst. Sci., 10, 2055-2066, doi:10.5194/nhess-10-2055-2010, 2010.

Mirza, S. A. and MacGregor, J. G.: Variations in dimensions of reinforced concrete members, J. Struct. Div., 105, 751-766, 1979.

Mosley, B., Bungey, J., and Hulse, R.: Reinforced Concrete Design: to Eurocode 2, Palgrave Macmillan, 6th Edn., 2007.

Naaim, M., Faug, T., Naaim, F., and Eckert, N.: Return period calculation and passive structure design at the Taconnaz avalanche path, France, Ann. Glaciol., 51, pp. 89-97, 2010.

Nielsen, M. and Hoang, L.: Limit Analysis and Concrete Plasticity, CRC Press, Boca Raton, FL, USA, 2011.

Papathoma-Köhle, M., Kappes, M., Keiler, M., and Glade, T.: Physical vulnerability assessment for alpine hazards: state of the art and future needs, Nat. Hazards, 58, 1-36, 2010.

Pasanisi, A., Keller, M., and Parent, E.: Estimation of a quantity of interest in uncertainty analysis: Some help from Bayesian decision theory, Reliability Eng. System Safety, 100, 93-101, 2012.

Peyras, L., Carvajal, C., Felix, H., Bacconnet, C., Royet, P., Becue, J.-P., and Boissier, D.: Probability-based assessment of dam safety using combined risk analysis and reliability methodsapplication to hazards studies, Euro. J. Environ. Civil Eng., 16, 795-817, 2012.

Saltelli, A., Annoni, P., Azzini, I., Campolongo, F., Ratto, M., and Tarantola, S.: Variance based sensitivity analysis of model output. Design and estimator for the total sensitivity index, Computer Phys. Communications, 181, 259-270, 2010.

Sawczuk, A. and Jaeger, T.: Grenztragfdhigkeits-Theorie der Flatten, Springer-Verlag, 1963.

Sobol, I.: Global sensitivity indices for nonlinear mathematical models and their Monte Carlo estimates, Math. Comput. Simulation, 55, 271-280, 2001.

Sovilla, B., Schaer, M., and Rammer, L.: Measurements and analysis of full-scale avalanche impact pressure at the Vallee de la Sionne test site, Cold. Reg. Sci. Technol., 51, 122-137, 2008.

Thibert, E., Baroudi, D., Limam, A., and Berthet-Rambaud, P.: Avalanche impact pressure on an instrumented structure, Cold Reg. Sci. Technol., 54, 206-215, 2008.

Wilhelm, C.: Quantitative risk analysis for evaluation of avalanche protection projects, in: Norwegian Geotechnical Institute, Oslo, Norway, 1998. 


\section{Appendix A}

Table A1. Nomenclature.

\begin{tabular}{|c|c|}
\hline$\rho_{\mathrm{s}}$ & density of steel \\
\hline$l_{x}$ & length of the slab \\
\hline$l_{y}$ & height of the slab \\
\hline$h$ & thickness of the slab \\
\hline$f_{\mathrm{c} 28}$ & cylinder characteristic compressive strength of concrete (age, 28 days) \\
\hline$f_{\mathrm{bc}}$ & compressive strength of concrete \\
\hline$f_{\mathrm{t}}$ & tensile strength of concrete \\
\hline$f_{\mathrm{y}}$ & steel yield strength \\
\hline$\epsilon_{\mathrm{uk}}$ & ultimate tensile strain of the steel \\
\hline$\gamma_{\mathrm{b}}, \gamma_{\mathrm{s}}$ & safety coefficients on concrete and steel strength \\
\hline$q_{\mathrm{ULS}}, q_{\mathrm{ALS}}, q_{\mathrm{Elas}}, q_{\mathrm{YLT}}$ & $\begin{array}{l}\text { characteristic loading at the ultimate limit state, at the accidental limit state, at the first cracks of the concrete } \\
\text { in the tensile zone and at the collapse }\end{array}$ \\
\hline$\epsilon_{\mathrm{bc}}$ & ultimate compressive strain of the concrete \\
\hline$\theta$ & loading time parameter \\
\hline$M_{\mathrm{AB}}$ & rational dimensioning moment \\
\hline$\mu_{\mathrm{AB}}$ & ULS rational dimensioning coefficient \\
\hline $\begin{array}{c}d \\
z\end{array}$ & effective depth of the RC cross section \\
\hline $\begin{array}{l}z \\
\beta_{y}, \beta_{x}\end{array}$ & lever arm in the section \\
\hline $\begin{array}{l}\beta_{y}, \beta_{x} \\
v\end{array}$ & Bares coefficient \\
\hline $\begin{array}{l}\nu \\
W_{\text {int }}\end{array}$ & Poisson coefficient \\
\hline $\begin{array}{l}W_{\text {int }} \\
W_{\text {ext }}\end{array}$ & internal virtual work \\
\hline$W_{\text {ext }}$ & external virtual work \\
\hline$n_{\mathrm{L}}$ & number of yield lines \\
\hline$M_{\mathrm{p}}^{i}$ & unitary plastic moment along the $i$ th line \\
\hline$L_{i}$ & length of the $i$ th line \\
\hline$\theta_{i}$ & rotation angle of the $i$ th element \\
\hline$\delta(x, y)$ & displacement matrix \\
\hline$q$ & uniform load \\
\hline$\alpha_{1}, \alpha_{2}$ & angles of YLT patterns \\
\hline$P_{\mathrm{f}}$ & failure probability \\
\hline$r$ & resistance of the structure \\
\hline$s$ & solicitation \\
\hline$\alpha$ & significance level of confidence interval \\
\hline$f_{\mathrm{R}}(r)$ & probability density function of the resistance \\
\hline$S_{i}$ & first-order Sobol sensitivity coefficient \\
\hline$S_{\mathrm{Ti}}$ & total Sobol sensitivity coefficient \\
\hline$\alpha_{\mathrm{c}}$ & coefficient from the JCSS distribution \\
\hline
\end{tabular}

